\title{
A CULTURA HISTÓRICA NO RPG O DESAFIO DOS BANDEIRANTES: elementos cognitivos, politicos e religiosos
}

\author{
Caio Cobianchi da Silva*
}

\begin{abstract}
RESUMO: Neste artigo, o role-playing game é analisado sob o prisma do conceito de cultura histórica de Jörn Rüsen. Por meio de artefatos culturais como o RPG, os jovens constroem conhecimentos a respeito de determinadas experiências históricas e passam a atribuir sentido a elas. Conhecendo melhor esses artefatos, podemos partir deles para possibilitar uma aprendizagem histórica crítica e que não esteja desconectada da cultura histórica disponível. Dito isso, o presente artigo analisa como o jogo $O$ Desafio dos Bandeirantes estetiza as dimensões cognitiva, política e religiosa da cultura histórica.

PALAVRAS-CHAVE: RPG, Cultura Histórica, Bandeirantes, Educação Histórica.

\section{Historical Culture in RPG O Desafio dos Bandeirantes: cognitive, political and religious elements}

\begin{abstract}
In this article, the role-playing game is analyzed from the perspective of Jörn Rüsen's concept of historical culture. Through cultural artifacts such as RPG, young people build knowledge about certain historical experiences and begin to attribute meaning to them. By getting to know these artifacts better, we can start from them to enable a critical historical learning that is not disconnected from the available historical culture. That said, this article analyzes how the game $O$ Desafio dos Bandeirantes aestheticises the cognitive, political and religious dimensions of historical culture.

KEYWORDS: RPG, Historical Culture, Bandeirantes, Historical Education.
\end{abstract}

\section{La Cultura Histórica en el JDR O Desafio dos Bandeirantes: elementos cognitivos, políticos y religiosos}

RESUMEN: En este artículo, se analizará el juego de rol bajo el concepto de cultura histórica de Jörn Rüsen. Valiéndose de artefactos culturales como el JDR, los jóvenes construyen unos conocimientos acerca de determinadas experiencias históricas y se les atribuyen un significado. Al conocer mejor estos artefactos, es posible basarnos en ellos para ofrecernos un aprendizaje histórico crítico que no esté desconectado de la cultura histórica disponible, por lo cual este artículo analizará cómo resultan estéticas en el juego $O$ Desafio dos Bandeirantes las dimensiones cognitivas, política y religiosa de la cultura histórica.

PALABRAS CLAVES: JDR, Cultura Histórica, Bandeirantes, Educación Histórica.

\footnotetext{
*Doutorando em História pela Universidade Federal de Mato Grosso (UFMT). Professor de História efetivo da Secretaria de Estado de Educação de Mato Grosso, município de Cuiabá (SEDUC-MT). Contato: Rua Piauí, nº7, quadra 91, 78055-458, CPA II, Cuiabá-MT, Brasil. E-mail: caiocobianchi@hotmail.com. ORCID: https://orcid.org/0000-0003-4346-3825
} 
RPG é a sigla utilizada como abreviação para o termo role-playing game, que pode ser traduzido como jogo de interpretação de papéis. Grosso modo, pode-se entendê-lo como um jogo no qual os participantes interpretam personagens criados por eles mesmos, como em um teatro improvisado, tomando decisões e enfrentando desafios em resposta à história construída pelo narrador, conhecido como mestre do jogo. Neste artigo, o RPG é analisado sob o prisma do conceito de cultura histórica de Jörn Rüsen.

Oficialmente, o RPG surgiu nos Estados Unidos na década de 1970. Mas, suas raízes remetem a um amálgama entre práticas muito antigas e jogos de simulação de batalha. Os jogos de guerra contemporâneos surgiram no início do século XIX, quando militares da Prússia os utilizavam no planejamento de táticas e simulações de manobras de combate. $\mathrm{O}$ Kriegspiel era praticado manipulando-se peças que representavam exércitos num grande tabuleiro de areia. Posteriormente, as demais nações europeias também passaram a utilizá-lo. Porém, os jogos de guerra para amadores só começaram a se popularizar depois da publicação de Little Wars em 1913, que trazia um conjunto de regras simples para esse formato ${ }^{1}$.

Em 1966, ocorreu nos Estados Unidos a publicação da obra O Senhor dos Anéis, de J. R. R. Tolkien, que se tornou febre entre os adolescentes e cultivou o gosto pelas histórias medievais. Logo, os jogos de guerra passaram a adicionar elementos da fantasia medieval em sua formatação, dando origem aos War Games medievais. Em 1974, Gary Gygax e David Arneson lançaram o primeiro livro de RPG, denominado Dungeons \& Dragons, pela editora TSR, no formato de uma mistura entre os jogos de guerra e o universo de fantasia medieval criado por Tolkien. O RPG se aproximava de um jogo de estratégia com miniaturas, no qual as histórias consistiam em invadir catacumbas, matar monstros e pegar o tesouro ${ }^{2}$.

Desde sua primeira edição até os dias de hoje, novas edições e novos sistemas vêm sendo lançados, por diferentes editoras e autores, ajudando a redefinir e aperfeiçoar as características do jogo. Concentrando-se nos sistemas mais populares, pode-se dividir a história do RPG em três etapas, em uma classificação que segue uma linha temporal não muito rígida, pois os diferentes sistemas convivem entre si e possuem diversas edições e complementos.

Em sua primeira fase, os jogos de RPG possuíam uma visualidade inspirada em ilustrações de fábulas e contos de fadas do final do século XIX e início do século XX. O cenário mais frequente era o de fantasia medieval e os sistemas de regras eram mais quantitativos. Nessa fase, se encontra o já mencionado Dungeons \& Dragons. Em sua segunda fase, surge o GURPS (Great Unnamed Role-Playing System). Lançado em 1986 por 
Steve Jackson, consiste num sistema de regras genérico que possibilita a criação de aventuras em quaisquer cenários e épocas que a imaginação permitir. Sua visualidade recebe influência dos quadrinhos, mangás e do cinema. Já em sua terceira fase, surge Vampiro - A Máscara, com um sistema de regras flexível que tem por prioridade a interpretação (storyteller). Traz ênfase nos aspectos dramáticos do jogo, na personalidade dos personagens e em um clima de horror pessoal. Ajudou a popularizar a modalidade live-action, na qual os jogadores, que se caracterizam como os personagens, atuam como se estivessem em um palco de teatro, ou seja, interpretam não apenas as falas de seus personagens, mas os trejeitos e ações ${ }^{3}$.

Com o decorrer dos anos, o RPG passou a contar não só com inúmeras publicações, mas também com revistas especializadas que tratavam do jogo. Surgia um senso de comunidade, identificado com o universo nerd e cult. Por todo o mundo, ganhava força uma nova modalidade de jogo na qual o mais importante não era disputar batalhas e alcançar vitórias, mas interpretar personagens e criar cenários a partir de regras de ação e atuação negociadas e flexíveis a fim de se obter cada vez mais prazer pela aventura. As diversas obras de RPG surgiam como referências a regras, cenários e histórias que, junto a referências externas a filmes, livros e quadrinhos, possibilitavam aos jovens viverem em um mundo de faz-de-conta, que precisava ser levado a sério.

A Revista Dragão Brasil situa que GURPS, publicada pela Devir, foi a primeira edição de RPG de mesa a receber uma versão nacional em 1991. Logo, a editora carioca GSA lançava o primeiro RPG brasileiro, o Tagmar. A mesma editora lançaria ainda o primeiro RPG com tema nacional, $O$ Desafio dos Bandeirantes, que influenciou uma série de outros títulos que abarcam conteúdos da história do Brasil. Em livros finos, baratos, com regras simplificadas e temas históricos, a série Mini GURPS colocava a escola no horizonte do RPG. Em 2002, durante o X Encontro Internacional de RPG, em São Paulo, ocorreu o I Simpósio de RPG \& EDUCAÇÃO. Nos anos seguintes, a continuação desse evento e muitos outros vieram sendo realizados, firmando um campo bastante ativo a respeito do uso do RPG na educação e em suas diversas áreas.

Diversas pesquisas têm sido produzidas defendendo ou desaprovando a escolarização do RPG. Quanto ao uso de RPG nas aulas de História, há pesquisas que apontam para o poder motivador do RPG, como estímulo para a curiosidade intelectual e apreço pela disciplina ${ }^{4}$, e há pesquisas que o utilizam como forma de transmissão do conhecimento histórico, seja por meio de conceitos substantivos (escravidão $^{5}$ ) seja por meio de conceitos epistemológicos (fonte histórica ${ }^{6}$, narrativa ${ }^{7}$ ). 
Uma vez que determinados títulos de RPG adotam temas históricos em suas narrativas, é possível entendê-lo não como uma ferramenta didática útil para a transmissão de conhecimento histórico, mas como um artefato ligado à cultura histórica da sociedade que o geriu.

De acordo com Rüsen ${ }^{8}$, toda sociedade constrói determinadas formas de relação com o passado, lançando mão de determinadas representações temporais com sentido e significado para o entendimento do presente e para a expectativa do futuro. O conjunto dessas representações constitui o que o historiador denomina de cultura histórica. Nas sociedades modernas, ela contempla as diferentes estratégias da investigação científica, mas também da criação artística, da luta política, da educação escolar e de outros procedimentos da memória histórica pública. Nesse sentido, o RPG com tema histórico também se integra à cultura histórica disponível.

Segundo Rüsen ${ }^{9}$, a cultura histórica está determinada por fatores diversos e múltiplos que envolvem o pensar, o sentir, o querer, o valorizar e o crer. Esses fatores representam cinco dimensões elementares que se inter-relacionam e acentuam a percepção, a interpretação e a orientação temporais. São elas: a) cognitiva: as pretensões de validade através do plano argumentativo (ciência, escolas); b) estética: a congruência formal e performativa através da imaginação, artes, literatura, museus e meios de comunicação; c) política: a legitimidade enquanto fator de luta pelo poder; d) moral: a valorização do passado de acordo com as normas éticas e morais; e) religiosa: se relaciona com a fundamento último do sentido da vida, experimentado, crido, e vivido como transcendente.

Tendo em vista que a aprendizagem histórica ocorre através dos meios formais e informais através dos quais a cultura histórica se manifesta, parte-se do pressuposto de que o RPG tem grande potencial para a aprendizagem histórica não apenas em razão de seus conteúdos experienciais, mas também por sua influência na cultura juvenil através de seu caráter estético. Parte-se do conceito de cultura histórica pelo entendimento de que, na aprendizagem histórica, não é central apenas a preocupação com a fidedignidade das formas de apresentação do passado, "mas sim a avaliação de como determinadas leituras do passado [...] atuam na vida prática nas dimensões cognitiva, política ou estética"10.

O resultado da produção de sentido histórico pelos jovens que entram em contato com o RPG fica para um trabalho futuro. Todavia, antes de dar esse passo, é preciso analisar como se dá a estetização das experiências históricas por esse artefato. Afinal, segundo Rüsen ${ }^{11}$, as múltiplas formatações de sentido do tempo e sua mudança histórica dependem essencialmente 
dos meios pelos quais a experiência e a interpretação do tempo são transmitidas. Determinantes para a formatação da consciência do tempo são as modalidades em que a linguagem regula a comunicação humana.

Dito isso, apresenta-se no tópico a seguir uma análise de como determinada representação temporal é construída através da estetização de elementos cognitivos, políticos e religiosos pelo RPG $O$ Desafio dos Bandeirantes, título que marcou a introdução de temas nacionais e de uma abordagem mais pedagógica no Brasil.

\section{A cultura histórica no jogo $O$ Desafio dos Bandeirantes}

Os RPGs com tema histórico precisam construir não apenas um universo fantástico instigante, mas também precisam se ater ao contexto sobre o qual se debruçam com certa coerência a fim de fornecer elementos para que os jogadores se sintam imersos naquele outro tempo. Não seria correto dizer que, ao produzir suas narrativas, o fazem com a intenção de produzir verdade, mas que, por referenciá-las em um contexto histórico, lançam mão de uma compreensão que julgam plausível para o mesmo. No universo do jogo, ainda que sempre seja possível agregar outros elementos (históricos, literários), a própria fantasia não pode estar totalmente desassociada do contexto histórico de referência. No livro-jogo O Desafio dos Bandeirantes, por exemplo, a narrativa engloba elementos do folclore brasileiro (saci-pererê, curupira etc.) e não elementos da fantasia medieval (orcs, elfos etc.).

A análise da forma como os elementos cognitivos são apresentados não poderia deixar de começar pela própria capa do livro-jogo, a qual dispõe do título $O$ Desafio dos Bandeirantes: Aventuras na Terra de Santa Cruz e de uma ilustração de um bandeirante em luta com uma espécie de homem morcego, sendo observado por outro bandeirante e por um indígena, prestes a receber o ataque de outros monstros vindos dos ares. Enquanto o título apela para um clima aventuresco expresso pelos termos "desafio" e "aventuras", a ilustração também o faz ao optar por uma cena de combate, em um tom mais tenebroso, alaranjado. Mesclam-se o histórico e o ficcional. 
Figura 1 - Capa de O Desafio dos Bandeirantes (capa)

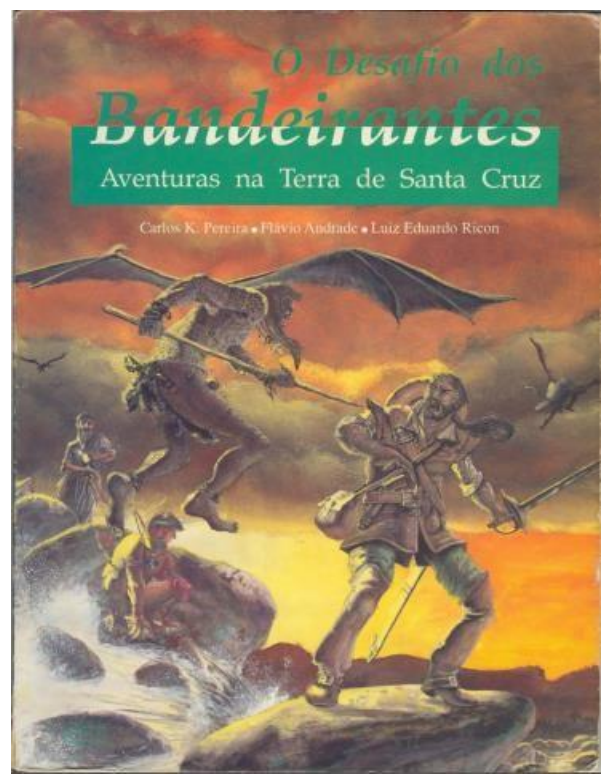

Fonte: O Desafios dos Bandeirantes, 1992.

A capa centrada em um homem branco atacado por um homem morcego não remete de imediato ao folclore brasileiro, posteriormente explorado na obra. É preciso desviar um pouco o olhar do centro para encontrar o indígena. Sendo o RPG mais jogado mundialmente o D\&D, ambientado no mundo medieval, a capa de $O$ Desafio parece tímida quanto a introduzir elementos incomuns ao público. Já na apresentação da obra encontramos uma tentativa de aproximação com os jogos já conhecidos:

É que O Desafio dos Bandeirantes é o primeiro role-playing game (RPG) com temas baseados na História e no folclore brasileiros, com a mesma emoção e os mesmos desafios de qualquer outro RPG de fantasia. Aqui você também pode ser um guerreiro destemido ou um poderoso feiticeiro. E também vai enfrentar criaturas perigosas e mágicas. E aqui também existem monstros tão mortais e aterrorizantes quanto os terríveis dragões. Só que com algumas diferenças importantes ${ }^{12}$.

Todavia, logo após tentar se aproximar do universo mais familiar, não deixa de destacar sua singularidade:

No mundo do Desafio dos Bandeirantes, você pode viver um corajoso bandeirante, explorando novas terras e se arriscando na floresta em busca de riquezas. Ou pode ser um bravo jesuíta, usando o poder da fé para combater as forças do mal. Se você 
quiser, pode aprender os segredos da natureza e se tornar um pajé, dominando essa magia poderosa. Ou pode viver um valoroso guerreiro índio, protegendo sua tribo dos monstros e perigos da floresta. E o seu personagem também pode ser um negro, trazido como escravo para o Novo Mundo, lutando pela sobrevivência com a força de sua coragem e o poder da magia de seus ancestrais ${ }^{13}$.

Observa-se que os recursos estéticos, logo na apresentação da obra, incluem adjetivos que ornamentam as experiências históricas. Os sujeitos históricos conhecidos na escola, como o jesuíta, o índio e o escravizado ganham aqui as características de "bravo", "valoroso" e "corajoso".

Portanto, até aqui, há a disposição de personagens históricos adjetivados e relacionados a um clima de ação e aventura, em que o novo (índio, bandeirante, jesuíta) não abandona totalmente o conhecido (mesma emoção, mesmos desafios). Na capa, é possível observar a instrumentalização dos elementos cognitivos pela arte, da imaginação sobre o histórico. Na apresentação, os sujeitos históricos começam a ser historicizados (o poder da fé dos jesuítas, o guerreiro indígena que protege sua tribo, o negro trazido como escravo), mas sem abandonar o ficcional (magia poderosa, monstros da floresta).

Uma característica da série $O$ Desafio dos Bandeirantes é propor um cenário fictício, apenas inspirado no contexto histórico, trazendo semelhanças e diferenças em relação a ele. A seguir um trecho um pouco longo, que apresenta uma introdução ao cenário:

As aventuras deste RPG se passam na Terra de Santa Cruz, que é inspirada no Brasil Colônia do século XVII. Os jogadores viverão aventuras em um território ainda selvagem e inexplorado, enfrentando os perigos da selva, tribos hostis, feras perigosas e monstros estranhos.

As antigas superstições, mitos e lendas estão presentes e são reais. Assim como a magia, manipulada por representantes das três raças: branca, negra e indígena.

A Terra de Santa Cruz faz parte de um mundo fictício onde a história seguiu um curso similar à nossa, guardando algumas diferenças significativas. O Tratado de Santa Luzia entre a Igreja Católica e a Coroa Lusitana, por exemplo, proibiu o apresamento e a escravidão dos indígenas no Novo Mundo, protegendo as Missões Jesuíticas. O tráfico de escravos indígenas ainda subsiste, mas apenas de forma clandestina.

Em virtude destes fatos, a principal atividade dos bandeirantes no jogo é a procura por metais e pedras preciosas, o combate a tribos hostis e salteadores, a escolta de caravanas, o comércio entre as vilas da região e a exploração de novos territórios.

A Terra de Santa Cruz apresenta regiões bem colonizadas e outras totalmente inexploradas, como a América do Sul dessa época. Os povos que a habitam são semelhantes às civilizações pré-colombianas, mas no lugar de tupis, guaranis e incas, há jaguaris, maoáris e illimanis. Da mesma forma, os portugueses são conhecidos como lusitanos, os espanhóis como castelanos, os franceses como francos, e os holandeses como flandrinos ${ }^{14}$. 
Os autores ressaltam que sua intenção não é a de reconstruir o contexto histórico em sua integridade, mas a de construir pontes entre as realidades fictícia e não-fictícia de modo que os jogadores possam se sentir mais livres para se aprofundar no mundo da fantasia. Não se altera o fato de que os jogadores precisam evitar certa dose de anacronismo e manterem-se coerentes com a ambientação. O RPG é, pois, um jogo no qual um grupo de jogadores com os seus valores, crenças e linguagens levam-nas para um outro contexto no qual precisam se atentar às características vigentes nele, sejam elas mais ou menos referenciados em um contexto histórico.

Por um lado, os jogadores são relativamente livres para construir e interpretar seus personagens de acordo com suas próprias referências e preferências; por outro, precisam tentar despir-se de si mesmos para reconhecer e levar adiante a alteridade dos personagens (históricos ou não). No caso dos RPGs com tema histórico, essa alteridade é colocada em jogo pela própria memória histórica dos jogadores em diálogo com aquela mobilizada pelo livrojogo.

Os RPGs costumam disponibilizar algumas raças de personagens com características (físicas, morais) específicas que devem ser observadas pelos jogadores no processo de interpretação. Enquanto o D\&D, por exemplo, possibilita que os jogadores interpretem anões, elfos, orcs etc., $O$ Desafio optou por evitar a fantasia nessa etapa. Os jogadores devem interpretar uma das cinco raças disponíveis: branco, índio, negro, mulato e mestiço.

É importante que o jogador tenha em mente que essas raças estão descritas na forma como se apresentavam no século XVII. Os negros eram escravizados até fins do século XIX; os índios foram explorados e perderam muito de sua cultura; e os brancos se sentiam superiores e donos da verdade. Tudo isso faz parte de nossa História, e desprezar qualquer um desses fatos seria descaracterizar a proposta deste RPG, que é, basicamente, a sua ambientação inteiramente nacional. Há, é claro, algumas adaptações feitas para as regras do jogo e, também, para torná-lo mais agradável $^{15}$.

O trecho alimenta a ideia de que há a busca por certos critérios de verdade dentro do mundo da fantasia. Qualquer afirmação de que tudo vale no RPG pode ser facilmente contestada. Partindo do que foi exposto acima, a narrativa torna-se mais suscetível a uma crítica que não a considere livre do compromisso histórico. Duas críticas possíveis são a falta de contextualização da palavra mulato e a ausência da possibilidade de interpretar cafuzos. 
É interessante notar como $O$ Desafio, em sua tentativa de construir uma ambientação própria, cai num lugar comum cultura escolar ${ }^{16}$. São disponibilizadas quase duas páginas com os fatos da Terra de Santa Cruz, em ordem cronológica. Alguns deles:

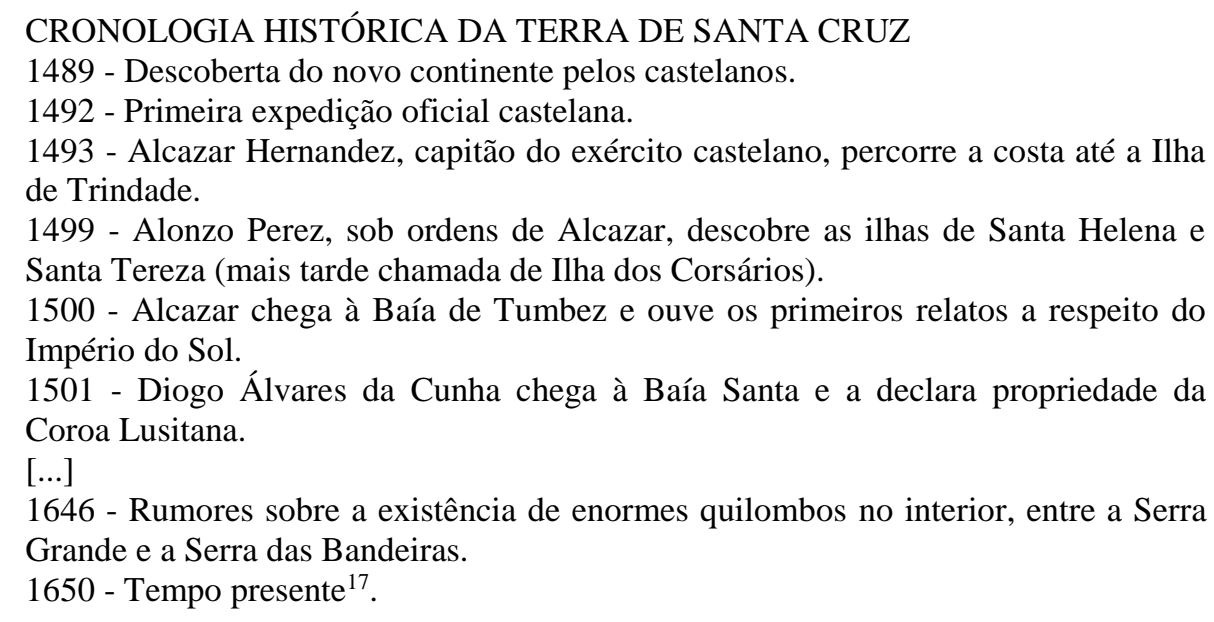

Tal organização lembrou-me de quando eu era estudante de ensino médio e lia com interesse o livro de História em volume único de Gilberto Cotrim, um calhamaço que trazia ao final a cronologia dos ditos "principais acontecimentos" da origem do mundo aos dias atuais. Para mim, "ser bom" em História significava conhecer e mesmo decorar aqueles fatos. . Encontram-se, pois, semelhanças quanto à apresentação de uma narrativa linear e expositiva, com datas, imagens, mapas e testemunhos para a ilustração.

Quanto às imagens, O Desafio é repleto de ilustrações que acompanham as descrições de cenários e personagens. As ilustrações em preto e branco de Mário Proença parecem apostar em um clima de aventura, mistério e tenebrosidade, trazendo o foco para o contexto de exploração das matas da Terra de Santa Cruz. 
Figura 2 - Os bandeirantes, por Mário Proença ${ }^{18}$.

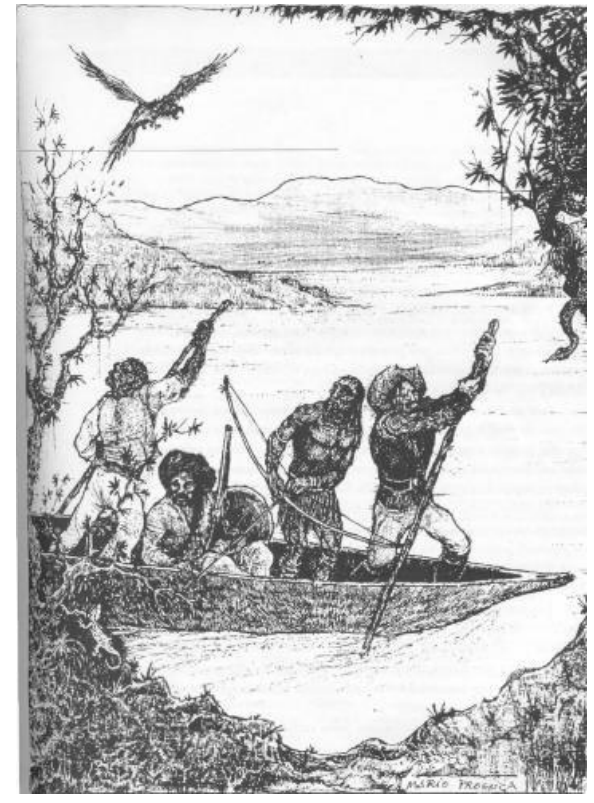

Fonte: O Desafio dos Bandeirantes, 1992.

Aposta-se, assim, na verossimilhança ao apresentar uma grande quantidade de características muito bem detalhadas da Terra de Santa Cruz. O livro-jogo traz uma lista de doenças, com seus sintomas e tratamentos, de armas e armaduras, de localidades, da flora e da fauna. É válido mencionar as Cartas do padre Bernardo Paes Freire a D. Gaspar de Bragança y Andrade, Arcebispo de El Rei que, colocada como "documento" de referência, descreve detalhadamente as situações cotidianas e as características da paisagem que o padre se depara em sua viagem.

Escrevo no ano da graça de Nosso Senhor de 1650 para dar relato a V. Eminência da minha viagem à cidade de Piratininga, em Santa Cruz, para avaliar o trabalho de catequese feito pelos irmãos de nossa companhia junto à população nativa local. [...] Após uma semana em São Vicente uni-me a uma caravana que ia a Piratininga vender e comprar mercadorias. A caravana constituía-se de quatro mercadores a cavalo, eu com um burrico que me foi cedido pelos irmãos, seis guerreiros como segurança, quatro mulas de carga, dez escravos índios, um rastreador mestiço e meia dúzia de agregados que precisavam ir a Piratininga por seus próprios interesses e acompanhavam a caravana pela segurança. A viagem durou cinco dias, durante os quais me inteirei das lendas e crendices locais com os índios e mestiços. Estes me contaram tamanhos desvarios sobre mulas sem-cabeça, meninos com pés virados, sereias nos rios, mulheres guerreiras, etc... que cheguei a temer pela sanidade dessa gente. $\mathrm{O}$ tempo viria a mostrar o quanto me enganava ${ }^{19}$.

A narrativa do padre Bernardo corrobora com a noção de compromisso histórico, aludindo a testemunhos históricos com linguagem própria, ainda que seja igualmente 
ficcional, como elemento para contextualização. Utiliza-se, ao mesmo tempo, de fatos reais (trabalho de catequese) e de lendas que, apesar de se mostrarem reais, são vistas, a princípio, pelo próprio padre como superstições. $\mathrm{O}$ trecho "o tempo viria a mostrar o quanto me enganava" traz o mistério necessário para que o leitor não desista de ler a carta de cinco páginas.

Seria desnecessário apresentar todo o livro-jogo a título de exemplificação, até mesmo porque jogar RPG não significa segui-lo à risca ou mesmo lê-lo por completo. O que se coloca em discussão é como os fatores cognitivos da cultura histórica, entendidos enquanto conjunto de conhecimentos produzidos e legitimados pela ciência, academias e escolas não são dispensados no RPG. De fato, recorre-se a elementos históricos legitimados pelos locais de saber como forma de apresentar um compromisso com o histórico no mundo da ficção. Alguns livros-jogo, como a série Mini GURPS, em títulos como Entradas e Bandeiras $^{20}$ e $O$ Descobrimento do Brasil ${ }^{21}$ chegam mesmo a se referenciarem em historiadores, tais como Affonso de Taunay e Sérgio Buarque de Holanda. Não é o caso de $O$ Desafio do Bandeirantes.

De qualquer forma, a questão é observar que o Desafio se integra à cultura histórica de seu tempo ao buscar construir uma ambientação que toma por base um contexto histórico real, e o faz lançando mão de uma perspectiva que dialoga com uma memória histórica já cristalizada e que traz elementos estéticos comuns aos manuais didáticos, por exemplo.

\section{O Desafio dos Bandeirantes: dimensão política}

A história é a história de constante luta, seja do embate entre gerações, interesses econômicos, políticos, religiosos, entre grupos étnico-raciais etc. Conhecer ou não essas lutas, participar ativamente ou não, não nos isenta de responsabilidade, pois a passividade significa o apoio ou no mínimo o consentimento com o mais forte. Aquele que estuda História é aquele que passa a se inteirar dessas lutas, que olha através da superfície e assim aprende a se posicionar.

Assim, as lutas pelo poder ocorreram, ocorrem e ocorrerão. Há aqueles que vencem e aqueles que perdem. Sendo que a estes cabe aceitar a dominação ou se opor a ela. Aqueles que aprendem a pensar historicamente passam a entender que a dominação e as próprias lutas não dizem respeito apenas ao presente, mas que foram construídas historicamente em um processo que se iniciou antes da própria vida e que seguirá adiante após a própria morte. 
Muitas vezes, as narrativas contadas pelo professor na aula de História dizem algo a respeito do outro que parece ter pouca ou nenhuma relação com o eu, com o mundo atual. Qual professor nunca ouviu a máxima: “para quê estudar História se todo mundo já morreu?”. Destaco brevemente a relevância do campo de pesquisa da Educação Histórica, a qual defende que a aprendizagem histórica deve partir sempre das carências de orientação do sujeito no presente rumo à construção de interpretações históricas que assumam a forma de narrativas com sentido para a vida presente e perspectiva de futuro.

No processo de produção de sentido histórico por meio da aprendizagem histórica, o princípio da multiperspectividade se mostra indispensável, pois possibilita a identificação (ou rejeição) dos sujeitos com as diferentes experiências históricas da contingência, permitindolhes reavaliar sua própria atuação nas lutas do presente, gerando orientação e motivação temporais.

As experiências históricas chegam a nós sempre através dos diferentes meios que as transmitem. O RPG é um artefato cultural, entre outros, que estetiza as experiências históricas e se integra à cultura histórica pelo seu potencial de geração de sentido para orientação. Os jogadores costumam interpretar diferentes raças de personagens que apresentam diferentes características, histórias, atributos e habilidades. Nesse processo, ele precisa reconhecer alteridade dos personagens interpretados, o que pode gerar um sentimento de identificação. Ao mesmo tempo que busca afirmar a singularidade de seu personagem, o jogador tem que dialogar com os demais a fim de tomar decisões coletivas ou mesmo individuais tendo em vista a reação dos demais.

Ao apresentar as raças de personagens jogáveis, os autores de $O$ Desafio, como que para se precaver, apresentam na contracapa que "esta é uma obra de ficção livremente inspirada na História e no folclore brasileiros. A obra não reflete as crenças dos autores, que condenam qualquer tipo de preconceito, discriminação ou violência". De início, já se pode entrever que o jogo adota como tema as histórias difíceis ${ }^{22}$ dos tempos de colonização. Se, como afirmam, a obra não reflete a crença dos autores, reflete sim uma perspectiva, uma forma de encarar o passado que não é neutra ou sem consequências para a vida atual.

Como já mencionado, O Desafio apresenta cinco raças para os jogadores interpretarem. Vejamos como elas são descritas:

O branco se sente superior às demais raças, podendo este sentimento se manifestar de diversas formas: uma relação senhor-escravo tradicional, de dominação, um desprezo profundo ou um paternalismo condescendente. 
O negro possui o estigma da escravidão. Sofre com o preconceito e a impossibilidade de ascensão social. Mesmo o negro livre (como a maioria dos negros aventureiros) é marginalizado e vê com desconfiança e revolta os opressores de seu povo.

Os índios são alvo de sentimentos mais variados. Apesar de também sofrerem com o preconceito, se fazem respeitar como inimigos ou como peças estratégicas na conquista do Novo Mundo. Sua atitude com os invasores, sejam eles brancos ou negros, pode ser de amizade, desconfiança ou inimizade.

O mulato e o mestiço podem se identificar mais com um lado ou com o outro. Isto é, o mulato pode ser tratado como um negro ou ter maior aceitação na sociedade colonial. Da mesma forma, o mestiço conta com a vantagem de ser visto como elemento colonizador pela metrópole. Como desvantagem, pode ser visto com preconceito pelos irmãos indígenas ${ }^{23}$.

Como se vê, a narrativa busca apresentar as raças em múltiplas facetas, de modo que ao escolher uma delas, o jogador pode optar por uma ou outra característica ou mesmo apostar em outras. $\mathrm{O}$ branco varia entre o desprezo e o paternalismo perante os outros; o negro entre a estigma e a revolta; os índios entre a inimizade e amizade com os demais e, por fim, os mulatos e mestiços tendo que lidar com impasses ao se identificarem com um ou outro grupo.

Apesar da multiplicidade de experiências, o ponto de vista predominante que se busca reconstruir é o do bandeirante desbravador. Na apresentação de sua ambientação, O Desafio dos Bandeirantes sugere enredos que ajudam a entender essa assertiva:

Os jogadores viverão aventuras em um território ainda selvagem e inexplorado, enfrentando os perigos da selva, tribos hostis, feras perigosas e monstros estranhos. [...] a principal atividade dos bandeirantes no jogo é a procura por metais e pedras preciosas, o combate a tribos hostis e salteadores, a escolta de caravanas, o comércio entre as vilas da região e a exploração de novos territórios ${ }^{24}$.

Fica nítido que os vilões sugeridos são, sobretudo, aqueles que tradicionalmente ocupam a Terra de Santa Cruz e não aqueles que a conquistam no processo de colonização. O termo "tribos hostis" aparece duas vezes nessa introdução, assumindo, assim, o ponto de vista do bandeirante como fio condutor da narrativa.

Enquanto as possibilidades oferecidas para a interpretação dos brancos, no que se refere às características da raça, não o imbuem de fantasia - eles podem ser jesuítas, mercadores, exploradores, degredados etc. - as possibilidades de interpretar o indígena são apresentadas através de 18 tribos, divididas em três grupos: amistosas (que procuram cooperar com os brancos); hostis (conflitam com os brancos e com as tribos aliadas aos brancos) e especiais (pouco numerosas e com características excepcionais). A fantasia inunda a representação dos indígenas. Abaixo, um exemplo de tribo pertencente a cada grupo: 
[Amistosa] Caiapunas: Tribo que habita o sul das terras lusitanas (parte da Serra da Colônia até os pampas castelanos). São índios pouco amistosos, porém, a relação com os colonizadores varia muito de vila para vila. São fortes e muito resistentes, causando muitos problemas quando hostis. Movimentam-se com grande destreza pelos campos, se tornando praticamente invisíveis aos inimigos. Uma de suas fraquezas é a falta de união ${ }^{25}$.

[Hostil] Iaraupês: Pequena tribo que habita o vale do rio São Caetano do Sul, entre a Serra do Mar e a Serra das Bandeiras. Bastante organizada, hostil e canibal, é o principal pesadelo das bandeiras que tentam passar por sua região ${ }^{26}$.

[Especial] Cupendiepes: Raça hostil de índios com asas de morcego que habitam em cavernas nas montanhas. Atacam nas regiões próximas em grupos de 2d6, dando voos rasantes, usando lanças ou machados para decapitar seus oponentes ${ }^{27}$.

Se, de um lado, o jogo aposta na ideia diversidade étnico-cultural para a narração do que se denomina genericamente de índios; por outro lado, a fantasia coloca determinadas tribos na posição de exóticas e hostis (hostis para quem?), enquanto a raça branca é, em seus aspectos biológicos e culturais, mais naturalizada.

Figura 3 - Tribos indígenas, por Mário Proença.
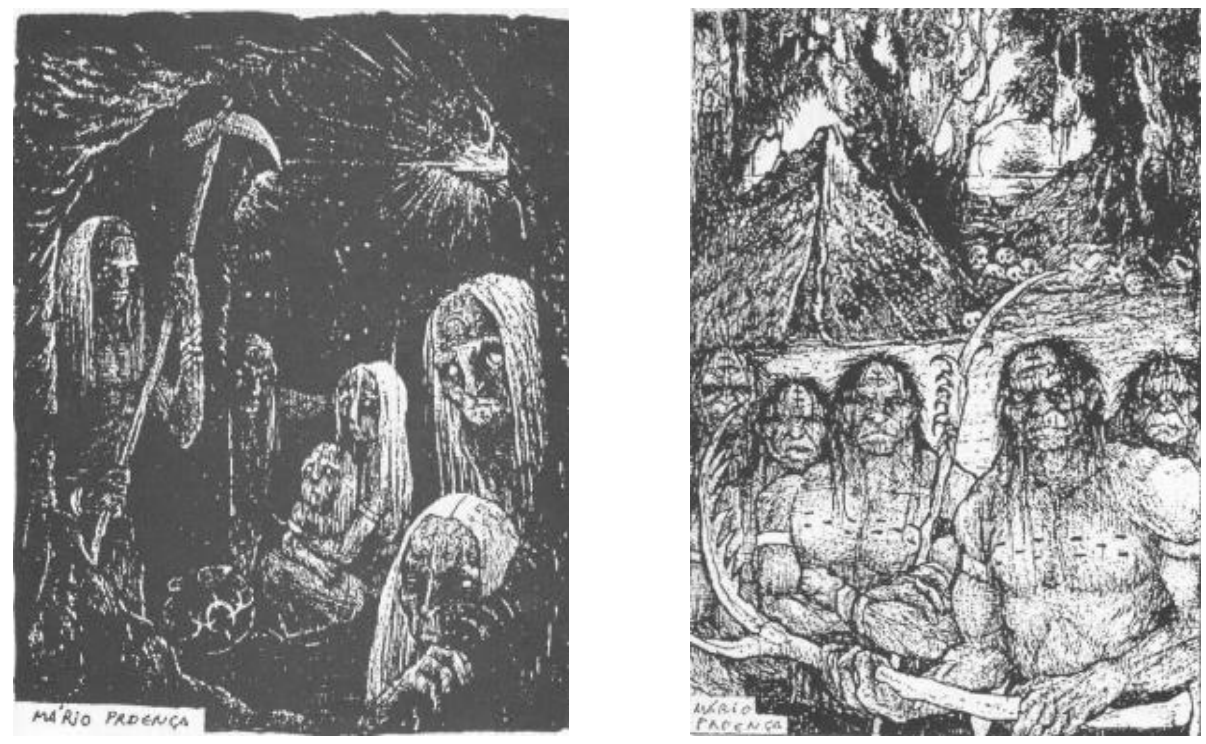

Fonte: O Desafios dos Bandeirantes, 1992.

Se pensarmos como dimensão política da cultura histórica a produção de sentido sobre as experiências no tempo em razão das lutas por poder e reconhecimento, podemos considerar que o RPG O Desafio dos Bandeirantes assume predominantemente o ponto de vista do colonizador. O bandeirante mesmo podendo ser representado por diferentes raças é aquele 
que vai enfrentar os desafios da Terra de Santa Cruz, colocada como região selvagem, exótica, perigosa e misteriosa.

No entanto, há que se notar que, se de uma parte, o livro-jogo fornece referências que expressam uma perspectiva histórica; de outra parte, essa perspectiva é sempre negociada pelos jogadores. Jogar RPG não é apenas entrar em contato com determinada imagem a respeito do passado, mas reconstruí-la para propósitos do jogo. Os jogadores buscam dar vida aos seus personagens através da arte e da história, tornando-os relevantes para a narrativa e buscando reconhecimento perante os demais. As experiências temporais das lutas por poder no passado são interpretadas tendo em vista os propósitos do jogo, mas também as lutas do tempo presente. Estão em jogo as dimensões cognitivas, estéticas e políticas da cultura histórica.

\section{O Desafio dos Bandeirantes: dimensão religiosa}

Em $O$ Desafio, cada raça escolhida para ser interpretada dispõe de uma lista de profissões a serem agregadas a ela, que incluem novas habilidades e características. Entre elas, algumas são qualificadas como portadoras de magia, capazes de manipular energias da natureza para obtenção de fenômenos sobrenaturais. São elas: pajé, feiticeiro de ferro e fogo, feiticeiro negro e o bruxo. Diferentemente dos portadores de magia, há os portadores de religião que, na linguagem do jogo, são aqueles que realizam seus encantos através da ação de divindades e, por isso, estão submetidos a um código de ética. O jesuíta e o sacerdote negro entram nessa classificação. O jogo considera, portanto, que nem toda relação com o sobrenatural pressupõe um código de ética.

Para a análise de como essas profissões são apresentadas, optou-se por não seguir a divisão do jogo, que faz a distinção mais em razão das regras do que por questões históricas. Neste tópico, optou-se por apresentar cada profissão de acordo com sua raça. O branco é o único que pode interpretar o jesuíta e divide o bruxo com o mestiço. Vejamos:

[Jesuíta:] Membro da Companhia de Jesus que veio para Terra de Santa Cruz com o objetivo de catequizar os índios e defender os colonos das forças demoníacas. O jesuíta é versado em medicina e combate as forças do mal e os entes sobrenaturais com o poder de sua fé. Para sobreviver em ambiente tão hostil, o jesuíta aprende técnicas de sobrevivência, persuasão e o manuseio de armas de fogo. Porém, como a valorização da vida é a crença mais básica do cristianismo, ele só recorrerá às armas em legítima defesa, e, mesmo assim, quando todas as outras possibilidades tiverem se esgotado.

Devemos lembrar que apenas personagens da raça branca podem ser jesuítas e que mulheres, é claro, não são jesuítas. 
O jesuíta desconfia do pajé e do sacerdote negro, e é totalmente antagônico ao bruxo e ao feiticeiro negro ${ }^{28}$.

[Bruxo:] Degredados da metrópole pela Santa Inquisição, os bruxos introduziram na Terra de Santa Cruz a magia oriunda das antigas tradições da raça branca. Temidos, rejeitados e perseguidos pela sociedade colonial, jamais devem se identificar como bruxos (para sua própria segurança) ${ }^{29}$.

O Desafio não divide as raças e profissões de personagens entre o bem e o mal, afinal, todos os jogadores são os heróis da aventura. Nesse sentido, não há uma religião oficial a ser adotada ou que seja colocada como correta. Cada personagem possui características definidas que lhe atribuem valores morais. O jesuíta, como adepto do cristianismo, busca combater o que acredita ser as forças do mal. Essas forças do mal podem ser relacionadas a monstros e ao próprio demônio, personagem disponível na aventura, ou, talvez, aos adeptos de outras crenças, pois é mencionado que ele "desconfia" do pajé e do sacerdote negro e é "totalmente antagônico" ao bruxo e feiticeiro negro. O jogo, portanto, constrói uma narrativa que prevê conflitos religiosos. É provável que o jogador que escolhe interpretar o jesuíta terá que lidar, de uma ou outra forma, com esses dilemas.

Figura 4 - O jesuíta, por Mário Proença.

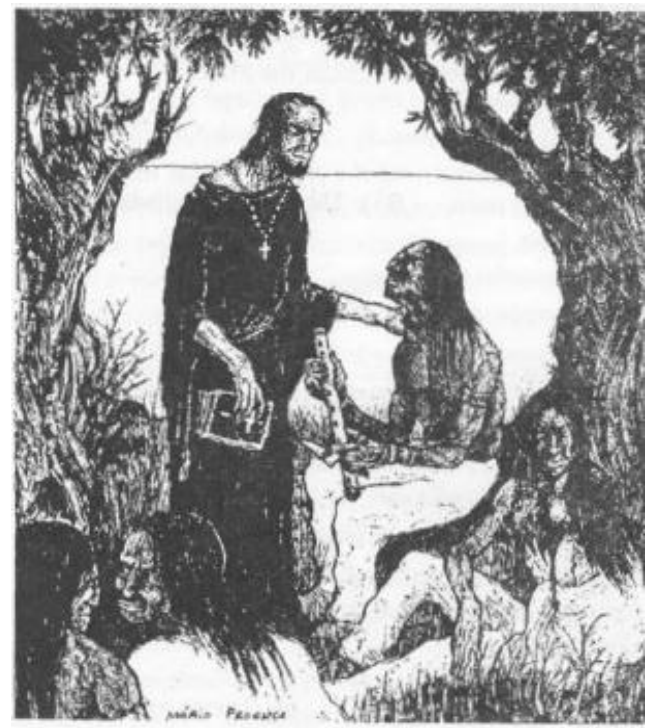

Fonte: O Desafio dos Bandeirantes, 1992.

Os bruxos receberam uma definição mais curta, que não lhes atribui objetivos, atitudes e valores a serem observados por quem os interpreta. Enquanto os jesuítas são colocados como aqueles que "valorizam a vida, buscam catequizar os indígenas e aprender técnicas de 
sobrevivência", os bruxos são definidos apenas como "portadores de magia oriunda das antigas tradições da raça branca, que são temidos, rejeitados e perseguidos”. Sem dúvida, interpretar alguém considerado temido ou rejeitado reflete no reconhecimento de sua alteridade. No entanto, pouca bagagem é fornecida para o jogador que opta por interpretar um bruxo, o que deixa mais vazão para a imaginação.

O negro e o mulato podem optar pelas mesmas profissões referentes ao domínio de magia e religião. São elas:

[Sacerdote negro:] O sacerdote negro é a ponte entre as nações negras e seus deuses - os Orixás. Incorporando o poder e a sabedoria dos orixás, o sacerdote negro busca proteger e orientar seu povo que foi trazido à força para o Novo Mundo como escravo.

Apenas durante a incorporação de um orixá o sacerdote negro pode utilizar a magia. Por sua ligação com a religião de seus ancestrais, ele está proibido de utilizar armas de fogo $^{30}$.

[Feiticeiro negro:] Este feiticeiro trabalha com forças sobrenaturais, extraindo seu poder dos espíritos. Sua magia recorre a diversos rituais de duração variável para atingir seus objetivos.

Os feiticeiros negros são mais temidos do que respeitados, principalmente pelo seu próprio povo. Sua presença é sempre motivo de desconfiança e temor ${ }^{31}$.

[Feiticeiro de ferro e fogo:] Esta escola de magia reflete o caráter guerreiro da raça negra manipulando esses dois elementos básicos. O feiticeiro de ferro e fogo distingue-se dos demais usuários de magia devido ao seu caráter notadamente bélico. É um guerreiro mágico ${ }^{32}$.

Foge aos limites desta pesquisa analisar criteriosamente as religiões de matriz africana em relação à coerência da perspectiva apresentada pelo RPG. Na verdade, o foco não é analisar a plausibilidade das interpretações, mas como elas são estetizadas. Ao jogador que optar por interpretar um feiticeiro de ferro e fogo, não há informações consideráveis sobre a postura a ser adotada, exceto a de que o mesmo deve se comportar como um guerreiro. Diferentemente do sacerdote negro e do feiticeiro negro. Enquanto o primeiro é aquele que protege e orienta seu povo e que não pode usar armas de fogo (código de ética), o segundo é mais temido do que respeitado. Outra diferença é que o sacerdote negro incorpora os orixás para realizar seus encantos enquanto o feiticeiro negro invoca espíritos.

$\mathrm{Na}$ exposição das regras de jogo referentes ao sacerdote negro, é realizada uma breve contextualização histórica:

Na visão afro, os Orixás são os deuses que governam o mundo e conferem poder aos sacerdotes. Cada Orixá controla um aspecto diferente da natureza e dos homens, possuindo personalidade e poderes diversos. Parte desse poder é concedido aos sacerdotes sob a forma de encantos. Ao incorporar o Orixá, o sacerdote é capaz de 
aprender alguns de seus encantos e utilizar seu poder. Para isso, o sacerdote tem que despender parte de seu poder divino ${ }^{33}$.

A esse personagem é oferecida uma lista de 15 orixás a serem incorporados, com o nome correspondente às crenças africanas (não ficcionais), uma breve descrição e um conjunto de encantos disponíveis. Por exemplo:

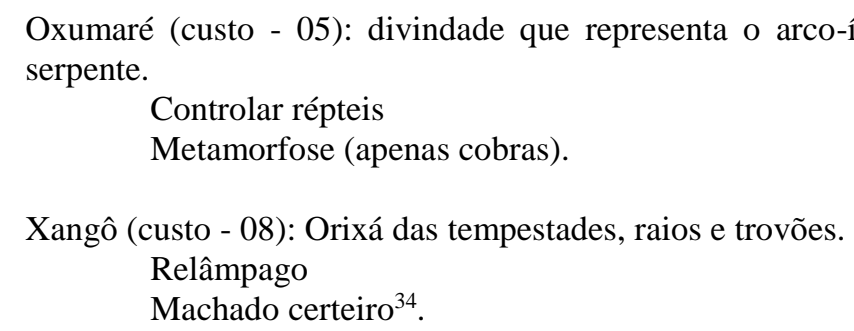

Na descrição dos orixás, não há informações sobre a forma como os jogadores devem narrá-los e interpretá-los ou sobre as formas de relação com o sacerdote que os incorpora. As referências para interpretação são bastante vagas. Por ser portador de religião, há a indicação de que o sacerdote negro segue um código de ética, entretanto, cada orixá possui uma personalidade. $\mathrm{O}$ jogador que escolhe esse personagem tem a responsabilidade de narrar ou encenar as diferentes incorporações de acordo com suas próprias concepções; o que pode ser delicado uma vez que vivemos em uma sociedade preconceituosa quanto às religiões de matriz afro.

Figura 5 - Os orixás, por Mário Proença.

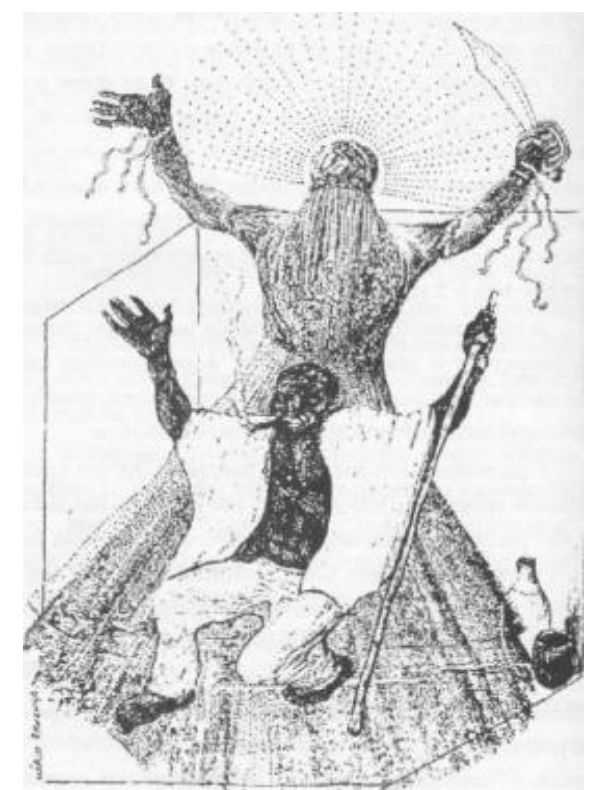

Fonte: O Desafio dos Bandeirantes, 1992. 
Diferentemente do sacerdote negro, o feiticeiro negro não incorpora as entidades, mas invoca os espíritos.

Apesar de manipular as energias da natureza como os demais feiticeiros, o feiticeiro negro precisa pedir ajuda aos espíritos para ter acesso a essas forças.

[...] Nem todos os espíritos servirão ao feiticeiro com total boa vontade. Existem os espíritos bons, os malignos e os que mantêm uma postura neutra, variando de acordo com a situação $0^{35}$.

Aqui há, portanto, uma distinção entre o bem, o neutro e o mal, que divide os onze espíritos disponibilizados. Essa distinção é associada à troca de favores entre o feiticeiro e os espíritos. Em troca de seus poderes, os espíritos bons não pedem nada. Os neutros podem pedir alguma oferenda, ritual ou trabalho. Já os malignos podem pedir favores mais sombrios, enganar ou simplesmente não querer partir. Nota-se que esta noção de mal, associada à crença africana, não existe para ser combatida, mas para ajudar os heróis da aventura de uma ou outra forma. Diferentemente da explanação do jesuíta que de fato procura combater o que considera ser diabólico. De qualquer forma, o jogo constrói uma representação dualista para o entendimento das religiões afro ao abordá-las dessa maneira.

Por fim, vejamos como o livro-jogo apresenta a profissão referente ao povo indígena:

[Pajé:] O pajé é o líder espiritual das tribos indígenas. Misto de sacerdote, feiticeiro e curandeiro, é responsável pela defesa mística de seu povo, usando tanto a magia da natureza como o poder de Tupã (a divindade suprema na crença de grande parte dos indígenas da Terra de Santa Cruz).

Como há apenas um pajé em cada tribo, os jogadores que escolherem esta profissão serão, inicialmente, apenas aprendizes, se tornando pajés ao atingirem o décimo nível de experiência [...].

O pajé se relaciona bem com aqueles que respeitam a floresta e a cultura indígena ${ }^{36}$.

Vale lembrar que o pajé é classificado no jogo como portador de magia e não de religião. Nas palavras do livro-jogo: “como o pajé é um ser dual, misto de feiticeiro e sacerdote, seus poderes originam-se da manipulação das forças da natureza (ou seja, não são “concedidos por Tupã”), não estando preso a nenhum código de ética específico"37. Portanto, o jogador que queira interpretar um índio e não opte por ser um guerreiro ou rastreador, tem como opção o pajé, responsável por defender o seu povo e a natureza. As descrições não vão além disso.

Na ótica de Vasques, o RPG precisa ser compreendido à luz do conceito de desencantamento do mundo de Max Weber. Ainda que trabalhe com temáticas religiosas, a quantificação e racionalização destas, a fim de torná-las passíveis de serem utilizadas na 
construção do universo ficcional do jogo, permite a comparação entre mitologias aproximando-se de estudos sociológicos e antropológicos. O RPG transforma elementos como deuses, semi-deuses, mistérios, etc., em gráficos, tabelas e números. "Com isto, o jogo mensura as forças divinas e/ou sobrenaturais através do cálculo para fins lúdicos. Os mitos no RPG são filtrados pela matemática"38.

Como se vê, apesar de o livro-jogo ser bastante extenso e detalhado, as descrições das raças e profissões também deixam bastante lacunas, o que reflete na maior autonomia dos jogadores para construírem seus personagens de acordo com seus conhecimentos prévios, referências, pesquisas e imaginação. No caso das profissões ligadas ao que o jogo denomina de magia e religião, o jogador precisa envolver seus personagens com forças transcendentais e crenças que podem estar bem distantes da sua própria religião (ou da falta dela). Nas palavras dos autores, "as antigas superstições, mitos e lendas estão presentes e são reais" na Terra de Santa Cruz.

\section{Considerações finais}

No presente artigo, buscou-se analisar a instrumentalização estética dos elementos cognitivos, políticos e religiosos pelo jogo O Desafio dos Bandeirantes, o primeiro RPG com temática nacional lançado no Brasil. Quanto a dimensão cognitiva, pode-se observar que, mesmo fazendo uso de elementos fantásticos, o jogo não deixa de buscar uma certa coerência com os elementos históricos, apostando na verossimilhança, contextualização, analogias, ressalvas e referência a "documentos" para evitar certo anacronismo e provocar uma sensação de plausibilidade.

Quanto à dimensão política, o jogo procura construir representações multifacetadas dos personagens históricos, que podem assumir diferentes características. Nota-se ainda que, devido a dinâmica do jogo, todas as raças de personagens jogáveis podem ser os heróis da aventura, sejam negros, indígenas ou brancos, desde que sejam escolhidos pelos jogadores. Por outro lado, ainda que evite vilanizar os personagens de acordo com a raça e profissão, ao assumir o bandeirantismo como fio condutor, coloca determinados povos indígenas como exóticos e hostis, o que pode levar à reprodução de uma visão eurocêntrica da história.

Em relação à dimensão religiosa, $O$ Desafio não adota uma religião oficial tomada como correta, apenas coloca a noção de bem e mal como inerente a algumas crenças. Se, por um lado, corre-se o risco de descrever mais coerentemente uma ou outra matriz religiosa; por outro, a quantificação característica do jogo pode auxiliar num trato mais histórico e menos 
enviesado. De qualquer forma, é preciso considerar a interpretação dos jogadores envolvidos ao mobilizarem suas ideias históricas tácitas em meio à cultura histórica em que são produzidas.

Até que ponto a instrumentalização estética que o RPG $O$ Desafio dos Bandeirantes faz das dimensões cognitivas, políticas e religiosas da cultura histórica interfere na produção de sentido histórico pelos jogadores é uma questão ainda em aberto. Todavia, é interessante observar a forma com que os diferentes artefatos culturais estetizam as experiências históricas. Uma aprendizagem histórica que ignora esse sentido já construído pode não ter sucesso em produzir novos. Conhecendo melhor esses artefatos, podemos partir deles para possibilitar uma aprendizagem histórica crítica e que não esteja desconectada da cultura histórica disponível.

\section{Notas}

${ }^{1}$ FRANCISCO, Ricardo J. S. Os jogos de interpretação de personagem e suas perspectivas no ensino de história. Dissertação (Mestrado em História) - Centro de Letras e Ciências Humanas, Universidade Estadual de Londrina. Londrina, 2011. 214f.

${ }^{2}$ ROCHA, Mateus de S. RPG: Jogo e conhecimento. O Role Playing Game como mobilizador de esferas do conhecimento. Dissertação (Mestrado em Educação) - Faculdade de Ciências Humanas, Universidade Metodista de Piracicaba. Piracicaba, 2006. 144f.

${ }^{3}$ No RPG de mesa, as ações dos personagens são mais faladas do que encenadas, diferentemente do live-action. .

${ }^{4}$ CARDOSO, Eli Teresa. Motivação escolar e o lúdico: o jogo RPG como estratégia pedagógica para o ensino de história. Dissertação (Mestrado em Educação) - Faculdade de Educação, Universidade Estadual de Campinas. Campinas, 2008. 141f.

${ }^{5}$ PEREIRA, Juliano da S. Uma máquina do tempo movida à imaginação: RPG e empatia histórica no ensino de história. Dissertação (Mestrado em História) - Centro de Letras e Ciências Humanas, Universidade Estadual de Londrina. Londrina, 2014. 149f.

${ }^{6}$ IONTA, Marilda. Aprender e ensinar história: os jogos de RPG na sala de aula. Revista Ponto de Vista, Viçosa, v. 6, n. 1, p. 23-29, 2010.

${ }^{7}$ FRANCISCO, Ricardo J. S. Os jogos de interpretação de personagem e suas perspectivas no ensino de história. Dissertação (Mestrado em História) - Centro de Letras e Ciências Humanas, Universidade Estadual de Londrina. Londrina, 2011. 214f.

${ }^{8}$ RÜSEN, Jörn. O que é a cultura histórica? Reflexões sobre uma nova maneira de abordar a História. In: SCHMIDT, MARTINS (Org.). Jörn Rüsen: contribuições para uma teoria da didática da história. Curitiba: W. A. Editores Ltda, 2016, p. 53-82.

${ }^{9}$ Idem. Teoria da História: uma teoria da história como ciência. Curitiba: Editora UFPR, 2015. 324p.

${ }^{10}$ SOUZA, Éder Cristiano de. Cinema e educação histórica: jovens e sua relação com a história em filmes. Tese (Doutorado em Educação) - Setor de Educação, Universidade Federal do Paraná. Curitiba, 2014. 357f, p. 113.

${ }^{11}$ RÜSEN, Jörn. Cultura faz sentido: orientações entre o ontem e o amanhã. Petrópolis, RJ: Vozes, 2014. 362p.

12 PEREIRA, Carlos E. K; ANDRADE, Flávio M; FREITAS, Luiz Eduardo R. O Desafio dos Bandeirantes: Aventuras na Terra de Santa Cruz. GSA - Entretenimento Editorial, Rio de Janeiro: 1992.

${ }^{13}$ Ibidem, apresentação (sem página).

${ }^{14}$ Ibidem, p. 02.

15 Ibidem, p. 05.

${ }^{16}$ Entendo o conceito de cultura escolar como "um conjunto de normas que definem conhecimentos a ensinar e condutas a inculcar, e um conjunto de práticas que permitem a transmissão desses conhecimentos e a 
incorporação desses comportamentos; normas e práticas coordenadas a finalidades que podem variar segundo as épocas (finalidades religiosas, sociopolíticas ou simplesmente de socialização)". JULIA, Dominique. A cultura escolar como objeto historiográfico. Tradução: Gizele de Souza. Revista Brasileira de História da Educação, Campinas, n. 1, p. 9-43, 2001, p. 10.

${ }^{17}$ PEREIRA, ANDRADE, FREITAS, op. cit., p. 86-87.

18 Ibidem, p. 03.

${ }^{19}$ Ibidem, p. 74.

${ }^{20}$ RICON, Luiz Eduardo. Mini Gurps: Entradas e Bandeiras. São Paulo: Devir, 1999. 129p.

${ }^{21}$ Idem. Mini Gurps: O Descobrimento do Brasil. São Paulo: Devir, 1999. 34p.

${ }^{22}$ Segundo Bodo Von Borries, histórias difíceis são aqueles episódios traumáticos difíceis de serem narrados em razão de sentimentos como a dor, a culpa e a vergonha. BORRIES, Bodo von. Lidando com histórias difíceis: tipos de reconciliação com danos e culpas históricas. In: SCHMIDT, FRONZA, NECHI (Org.). Jovens e Consciência Histórica. Curitiba: W.A. Editores, 2018, p. 33-54.

${ }^{23}$ PEREIRA, Carlos E. K; ANDRADE, Flávio M; FREITAS, Luiz Eduardo R. O Desafio dos Bandeirantes: Aventuras na Terra de Santa Cruz. GSA - Entretenimento Editorial, Rio de Janeiro: 1992, p. 06-07.

${ }^{24}$ Ibidem, p. 02.

${ }^{25}$ Ibidem, p. 88.

26 Ibidem, p. 89.

272 d6 significa 2 dados de 6 faces, refere-se ao dano causado em uma batalha segundo as regras do jogo. Ibidem, p. 90.

${ }^{28}$ Ibidem, p. 08.

${ }^{29}$ Ibidem, p. 09.

30 Ibidem, p. 08.

${ }^{31}$ Ibidem, p. 08-09;

32 Ibidem, p. 09.

${ }^{33}$ Ibidem, p. 29.

34 Ibidem, p. 30.

35 Ibidem, p. 26.

36 Ibidem, p. 08.

${ }^{37}$ Ibidem, p. 28.

${ }^{38}$ VASQUES, Rafael Carneiro. As potencialidades do RPG (role playing game) na educação escolar. (Mestrado em Educação). Faculdade de Ciências e Letras, Universidade Estadual de São Paulo. Araraquara, 2008. 179f, p. 61.

\section{Referências}

BORRIES, Bodo von. Lidando com histórias difíceis: tipos de reconciliação com danos e culpas históricas. In: SCHMIDT, FRONZA, NECHI (Org.). Jovens e Consciência Histórica. Curitiba: W.A. Editores, 2018, p. 33-54.

CARDOSO, Eli Teresa. Motivação escolar e o lúdico: o jogo RPG como estratégia pedagógica para o ensino de história. Dissertação (Mestrado em Educação) - Faculdade de Educação, Universidade Estadual de Campinas. Campinas, 2008. 141f.

FRANCISCO, Ricardo J. S. Os jogos de interpretação de personagem e suas perspectivas no ensino de história. Dissertação (Mestrado em História) - Centro de Letras e Ciências Humanas, Universidade Estadual de Londrina. Londrina, 2011. 214f.

IONTA, Marilda. Aprender e ensinar história: os jogos de RPG na sala de aula. Revista Ponto de Vista, Viçosa, v. 6, n. 1, p. 23-29, 2010. 
JULIA, Dominique. A cultura escolar como objeto historiográfico. Tradução: Gizele de Souza. Revista Brasileira de História da Educação, Campinas, n. 1, p. 9-43, 2001.

PEREIRA, Juliano da S. Uma máquina do tempo movida à imaginação: RPG e empatia histórica no ensino de história. Dissertação (Mestrado em História) - Centro de Letras e Ciências Humanas, Universidade Estadual de Londrina. Londrina, 2014. $149 f$.

RICON, Luiz Eduardo. Mini Gurps: Entradas e Bandeiras. São Paulo: Devir, 1999. 129p.

RICON, Luiz Eduardo. Mini Gurps: O Descobrimento do Brasil. São Paulo: Devir, 1999. $34 \mathrm{p}$.

ROCHA, Mateus de S. RPG: Jogo e conhecimento. O Role Playing Game como mobilizador de esferas do conhecimento. Dissertação (Mestrado em Educação) - Faculdade de Ciências Humanas, Universidade Metodista de Piracicaba. Piracicaba, 2006. $144 f$.

RÜSEN, Jörn. Cultura faz sentido: orientações entre o ontem e o amanhã. Petrópolis, RJ: Vozes, 2014. 362p.

RÜSEN, Jörn. O que é a cultura histórica? Reflexões sobre uma nova maneira de abordar a História. In: SCHMIDT, MARTINS (Org.). Jörn Rüsen: contribuições para uma teoria da didática da história. Curitiba: W. A. Editores Ltda, 2016, p. 53-82.

RÜSEN, Jörn. Teoria da História: uma teoria da história como ciência. Curitiba: Editora UFPR, 2015. 324p.

SOUZA, Éder Cristiano de. Cinema e educação histórica: jovens e sua relação com a história em filmes. Tese (Doutorado em Educação) - Setor de Educação, Universidade Federal do Paraná. Curitiba, 2014. 357f.

VASQUES, Rafael Carneiro. As potencialidades do RPG (role playing game) na educação escolar. (Mestrado em Educação). Faculdade de Ciências e Letras, Universidade Estadual de São Paulo. Araraquara, 2008. 179f. 